\title{
Contextualismo vs Minimalismo: um embate sobre a (in)dependência entre Semântica e Pragmática
}

\author{
Contextualism vs minimalism: a debate about the \\ (in)dependence between Semantics and Pragmatics
}

\section{Contextualismo vs Minimalismo: un debate sobre la (in) dependencia entre la Semántica y la Pragmática}

\author{
Daiana Amaral Jeremias ${ }^{1}$
}

\begin{abstract}
RESUMO: Este artigo tem como objetivo apresentar um debate entre duas correntes teóricas opostas: o minimalismo semântico e o contextualismo semântico. Mostraremos que o cerne dessa disputa faz referência às relações estreitas que a semântica e a pragmática possuem no que tange ao tratamento do significado de uma sentença e à possível influência do contexto em sua compreensão. Para os minimalistas Cappelen e Lepore (2005), o significado de uma sentença é definido em grande parte pelos seus elementos gramaticais; nessa concepção, a referência contextual não apresenta qualquer influência em seu conteúdo semântico, salvo os indexicais. Já os contextualistas como Recanati (2010) defendem que o contexto modaliza o conteúdo semântico de uma sentença: diferentes significados podem ser atribuídos a uma mesma sentença a depender do cenário dos atos de proferimento. A discussão entre essas diferentes abordagens parece uma alusão ao quão dependente ou independente a semântica é da pragmática, se elas estão ou não em relação de interface no tratamento do significado e do contexto. Se considerarmos a concepção minimalista, a semântica e a pragmática são áreas de estudos separadas; porém, se considerarmos a concepção contextualista, essas áreas são interdependentes, ou seja, as condições de verdade de uma sentença dependem da informação contextual do ato de fala.
\end{abstract}

PALAVRAS-CHAVE: Contextualismo. Minimalismo. Semântica. Pragmática.

ABSTRACT: This paper has as its main goal to present the debate between two main opposite theoretical trends: semantic minimalism and semantic contextualism. We shall argue that the core of their dispute is mainly about close relationship between semantics and pragmatics on what concerns the meaning of a sentence and its possible influence of the context of utterance on its understanding. To minimalists

\footnotetext{
${ }^{1}$ Doutaranda do programa de pós-graduação em Linguística da Universidade Federal de Santa Catarina. Contato: daianaah@hotmail.com
} 
Cappelen and Lepore (2005), the meaning of a sentence is largely determined by its grammatical components; according to them, the context of utterance does not influence the semantic content of a sentence, except for the case of indexicals. The contextualists, such as Recanati (2010), on the other hand, argue that the context modalizes the semantic content of a sentence: different meanings may be attributed to the same sentence, depending on the sense of the utterance. The debate between these two distinct approaches seems to allude to how far does semantics depends on pragmatics, whether they are in a relation when it comes to deal with meaning and context. When we take minimalism into account, semantics and pragmatics are separated research areas; however, when we take the contextualist approach, these areas are largely dependent on each other; that is, the truth conditions of a sentence depend on the contextual information about the speech act.

KEY-WORDS: Contextualism. Minimalism. Semantics. Pragmatics.

RESUMEN: Este artículo tiene como objetivo presentar un debate entre dos corrientes teóricas opuestas: el minimalismo semántico y el contextualismo semántico. Mostraremos que el núcleo de esta disputa hace referencia a las relaciones estrechas que la semántica y la pragmática poseen en lo que se refiere al tratamiento del significado de una sentencia y la posible influencia del contexto en su comprensión. Para los minimalistas Cappelen e Lepore (2005), el significado de una sentencia es definido en gran parte por sus elementos gramaticales; en esa concepción, la referencia contextual no presenta ninguna influencia en su contenido semántico, salvo los indexicales. Los contextualistas como Recanati (2010) defienden que el contexto modifica el contenido semántico de una sentencia: diferentes significados pueden ser atribuidos a una misma sentencia dependiendo del escenario de los actos de pronunciamiento. La discusión entre estos diferentes enfoques parece una alusión a cuán dependiente o independiente de la semántica es de la pragmática, si están o no en relación de interfaz en el tratamiento del significado y del contexto. Si consideramos la concepción minimalista, la semántica y la pragmática son áreas de estudios separados; sin embargo, si consideramos la concepción contextualista, esas áreas son interdependientes, o sea, las condiciones de verdad de una sentencia dependen de la información contextual del acto del habla.

PALABRAS-CLAVE: Contextualismo. Minimalismo. Semántica. Pragmática.

\section{Introdução}

No presente trabalho, pretendemos retomar as discussões acerca do Minimalismo semântico e do Contextualismo semântico. A saber, as duas vertentes defendem teses contrárias no que tange ao estudo do significado de uma sentença. A primeira defende que o conteúdo semântico pode ser compreendido quase que exclusivamente através dos constituintes gramaticais de uma sentença, de modo que qualquer interferência contextual pode ser 
atribuída apenas a um conjunto limitado de elementos, todos eles marcados na própria sintaxe da sentença. O contextualismo, ao contrário, defende que o conteúdo semântico de uma sentença depende pesadamente de informação contextual que podemos depreender da situação de conversação, ou seja, de fatores pragmáticos, externos ao material que é fornecido pela sentença. Estes influenciam no significado, fazendo com que diferentes condições de verdade sejam atribuídas para uma mesma sentença, a depender do contexto. Pretendemos apresentar as duas concepções de modo a trazer à luz o cerne da disputa entre estas duas vertentes. Como procuraremos argumentar, os próprios debatedores parecem perceber que tratam de concepções diferentes acerca do alcance e função da semântica.

Para tanto, o presente artigo será dividido em seções nas quais serão delimitados os conteúdos a serem abordados. Primeiramente, faremos uma exposição da problemática, tentando trazer o ponto central da questão que está por trás do embate Minimalismo x Contextualismo. Através de exemplos, buscaremos contextualizar as duas teorias e apresentaremos as principais características que se destacam em cada uma delas no trato da Semântica e da Pragmática.

Na segunda seção, trataremos do minimalismo semântico. Nela, faremos uma apresentação dos seus principais pressupostos acerca do estudo do conteúdo semântico de uma asserção e do que se apresenta contra a teoria contextualista. Utilizaremos o livro "Insensitive Semantics-A Defense of Semantic Minimalism and Speech Act Pluralism" de Cappelen e Lepore (2005) como principal referência do tema.

$\mathrm{Na}$ terceira seção, apresentaremos os pressupostos do contextualismo, buscando trazer as justificativas dos teóricos da área sobre a rejeição da semântica minimalista. Nela, mostramos como as inferências pragmáticas podem exercer influência na compreensão de uma sentença, ou seja, em seu conteúdo semântico. Dentro da teoria contextualista, há tanto autores moderados quanto outros mais radicais e, como buscamos uma concepção 
intermediária, que de certa forma não se distancie tanto de uma teoria mais formalista, traremos referências de Recanati (2010) do livro Truth-conditional pragmatics.

Na quarta seção, apresentaremos um panorama da discussão, buscando ressaltar o cerne da disputa entre contextualistas e minimalistas. Aparentemente, há uma disputa acerca da abordagem mais correta para a compreensão do significado de uma sentença. Esta abordagem deve ou não permitir a influência do contexto na determinação do significado? Como veremos, uma distinção entre o conteúdo semântico de uma sentença e conteúdo de atos de fala pode esclarecer que o debate é não apenas acerca de como se determinar o significado de uma sentença, mas também qual a tarefa e escopo da própria semântica.

\section{Introduzindo o embate entre contextualistas e minimalistas}

Nesta seção, trataremos de alguns pontos que nos permitirão compreender a oposição entre o Minimalismo Semântico e o Contextualismo, em outras palavras, o que se apresenta de específico na abordagem do significado em cada uma delas que permite compreendê-las como teses em direta oposição.

Comecemos tratando do minimalismo semântico. De modo bastante resumido, poderíamos caracterizar o minimalismo semântico como a tese segundo a qual há apenas um pequeno conjunto de expressões cujos significados são sensíveis ao contexto. Em outras palavras, o contexto interfere apenas minimamente para se fixar o significado de uma sentença. Dentre as expressões que se encontram neste conjunto básico, podemos mencionar algumas expressões dêiticas, como "aquele", "aquela", "isso", pronomes pessoais, como "eu", "ela", e advérbios de tempo e lugar, como "ontem", amanhã, "hoje", "aqui" e "lá". Com exceção das expressões do conjunto básico, 
como já mencionamos, todas as outras são insensíveis ao contexto quando se trata de determinar o conteúdo semântico de uma sentença.

Deve ficar claro que a caracterização acima ainda não especifica como deve ser entendido e determinado o conteúdo semântico de uma sentença (o minimalismo é neutro acerca do caráter específico que a própria teoria semântica deve tomar). De modo geral, defensores do minimalismo podem apelar para alguma teoria sobre proposições, de modo que o conteúdo semântico é expresso por uma proposição. Isso nos leva ao campo da metafísica, área da filosofia que é explorada de modo breve em Cappelen e Lepore (2005). Para tornar a ideia básica do minimalismo mais clara, buscaremos expor o ponto principal através de exemplo. Considere a sentença:

a) Maria possui muitos livros antigos.

Nela, gramaticalmente, temos uma relação entre os constituintes que nos permite, em um primeiro plano, compreender que há uma relação entre um possuidor, que neste caso vem a ser a própria Maria, e os objetos que ela possui, os quais se apresentam em um determinado estado. Segundo a tese minimalista, o significado dessa sentença deve ser o mesmo para qualquer ouvinte. Em outras palavras, enquanto estivermos tratando apenas do seu significado, o conteúdo semântico da sentença em 'a' é fixo, uma vez que seja estabelecida a referência do elemento "antigos". Isso deve ser garantido, independentemente de onde e quem participa dessa conversação na qual a sentença foi dita, e de quais propósitos se tinha ao pronunciá-la.

Contra esta proposta de um conteúdo semântico estável, o Contextualismo foca suas atenções no modo como o conteúdo de um proferimento, ou segundo nossa compreensão, dos atos de fala, pode ser influenciado pelo contexto no qual uma sentença é proferida. Segundo esta concepção, de modo geral, fatores externos à sentença influenciam diretamente no modo como uma mesma sentença pode ser compreendida 
quando asserida em diferentes contextos. Para caracterizar a relação entre os atos de fala, que sofrem influência do contexto, e o significado da sentença, seu conteúdo semântico, o contextualismo faz uma conexão entre eles. Conforme colocam Cappelen e Lepore, para os contextualistas "[...] semantic content has to be closely connected to speech act content." (CAPPELEN; LEPORE, 2005, p. 4).

Para tentar compreender essa diferença que a sensitividade ao contexto parece ter na determinação de significado, tomamos o mesmo exemplo da sentença 'a' anterior, qual seja, "Maria possui muitos livros antigos". Segundo a análise contextualista, essa mesma sentença poderia ter sido proferida em contextos diferentes, dando a ela significados diferentes. Acabaria assim a alegada estabilidade do significado da sentença. Consideremos uma situação na qual "Maria" herdou uma biblioteca de uma tataravó, e os livros estão parcialmente devorados pelas traças, as páginas estão corroídas pelo mofo e quase se desmanchando pela ação do tempo. Nessa interpretação, consideramos "antigos" como o estado físico dos objetos "livros". Contudo, podemos considerar outro contexto no qual "Maria" comprou vários exemplares de Dickens, volumes de capa dura, com ilustrações, cheiro de livro novo. Nessa condição, as histórias narradas no livro são antigas, tanto referindo-se ao tempo em que foram escritas como também a valores e crenças partilhados na época em que o autor escreveu. Como vimos, a depender do contexto, diferentes significados são compreendidos para o sintagma "livros antigos". Exemplos similares podem ser fornecidos para outras sentenças.

A partir da breve explicação acima, pode-se depreender que para o minimalista, com exceção das expressões que fazem parte do conjunto básico, que precisam do contexto para fixar suas referências, o conteúdo semântico de uma sentença é independente do contexto de enunciação, portanto, o significado é constante, fazendo sentido se falar em um significado literal em muitos casos. Aquilo que é inferido através de atos de fala não exerce qualquer influência ou mudança no conteúdo significativo de uma proposição, pois ela é 
aquilo que se apresenta tal e qual. Para Cappelen e Lepore (2005), os atos de fala podem até depender do contexto (mais sobre isso em breve), mas não influenciam no conteúdo semântico da sentença.

Já o Contextualismo permite que interferências externas exerçam influência na compreensão do conteúdo semântico; segundo esta concepção, o contexto modula o significado, que por sua vez depende do ato de fala produzido. Nele, o sentido não pode ser dito literal, mas sim dependente de intuições acerca do contexto em que foi proferido, de modo que o contexto contribui essencialmente para influenciar estas intuições. Para Bezuidenhout (2002, p. 105),

"[...] what is expressed by the utterance of a sentence in a context goes beyond what is encoded in the sentence itself. Truth-conditional content depends on an indefinite number of unstated background assumptions"

As suposições de fundo ou mesmo situações contextuais podem mudar as condições de verdade de uma sentença. Assim, quando tratamos desses diferentes tratamentos estamos lidando com uma diferença já explorada por outros estudiosos, e ao nos depararmos com essas confrontações estamos lidando com a linha tênue entre o que é Semântica e o que é Pragmática. Como veremos, este parece ser o centro do debate entre estas duas correntes, e como ambos os lados parecem reconhecer, a fronteira (se existe uma) é um tanto quanto nebulosa. Apesar dessas áreas de estudo terem definições aparentemente precisas, ou seja, semântica definida tradicionalmente como o estudo do significado e a pragmática o estudo da linguagem em uso, os termos são bastante complexos (LEVINSON, 2007), e o foco do debate está principalmente em se determinar qual a influência do contexto na semântica.

Desse modo, conforme apresentaremos mais adiante com mais vagar, nos parece que o Minimalismo Semântico se ocupa da semântica dos constituintes da sentença e de como eles contribuem para o significado da sentença, enquanto que o contextualismo enfatiza aspectos da Pragmática, focando no conteúdo dos atos de fala. Contudo, este último parece considerar 
níveis de interface entre essas duas áreas, já que o contexto, segundo a teoria, influencia no significado da asserção. Por outro lado, o Minimalismo não recusa a presença do contexto, porém estabelece um "Basic Set of Context Sensitive Expressions" (CAPPELEN; LEPORE, 2005, p. 2), um grupo de expressões que "solicitam" o contexto para a compreensão da proposição. Além desse basic set ter um número de elementos limitados, ainda consideram que

\footnotetext{
All semantic context sensitivity (i.e., context sensitivity that affects the proposition semantically expressed) is grammatically triggered, i.e., it is triggered by a grammatically (i.e., syntactically or morphemically) articulated sentential componente. (CAPPELEN; LEPORE, 2005, p. 143).
}

Com isso, para o contexto exercer uma influência na compreensão dos constituintes é preciso que a combinação dos mesmos o exija.

Em que medida estas duas investigações são mesmo opostas e a disputa trata do mesmo tipo de problema é o que pretendemos articular na seção final de nosso trabalho. Primeiramente faremos, nas próximas duas seções, uma exposição mais cuidadosa de cada uma das vertentes.

\section{0 minimalismo semântico}

O minimalismo semântico é uma corrente teórica que, de certo modo, representava a concepção hegemônica até recentemente, na qual uma sentença tem seu conteúdo semântico definido pelos elementos gramaticais que a compõem. Nessa sentença, o significado é o mesmo para qualquer situação de conversação, é estável. Para essa vertente, o contexto não apresenta influência direta ou mesmo uma mudança na compreensão semântica de uma proposição; segundo Cappelen e Lepore (2005, p. 143), "the semantic content of a sentence $S$ is the content that all utterances of $S$ share. It is the content that all utterances of $\mathrm{S}$ express no matter how different their contexts of utterance are." 
Nesse sentido, uma sentença com valor $\mathrm{x}$ precisa ser compreendida por qualquer ouvinte como tendo significado $x$ e não y. Se dissermos que "O sol está forte", o elemento sol precisa ser compreendido pelos participantes do discurso como sendo o mesmo e único sujeito, denotando o mesmo objeto. Obviamente, para os contextualistas, a percepção de mundo e também física de cada falante/ouvinte vai influenciar na modulação de compreensão do proferimento.

Como pressuposto teórico, utilizaremos como principal referência o livro "Insensitive Semantics - A Defense of Semantic Minimalism and Speech Act Pluralism" de Cappelen e Lepore (2005). Em sua tese, segundo os autores, o minimalismo tem como bases centrais os seguintes postulados:

i) Uma das proposições expressas pelo proferimento de uma sentença é exatamente a proposição que representa o conteúdo semântico do proferimento.

ii) A existência de tal proposição que seja o conteúdo semântico de uma sentença é um pressuposto de qualquer teoria que pretenda ser explicação razoável da comunicação;

iii) Para que o contexto exerça influência sobre o conteúdo semântico do proferimento de uma sentença, é preciso que os constituintes da sentença assim o requeiram; em outras palavras, os componentes da sentença que requerem determinação semântica contextual são marcados sintaticamente.

iv) Há um grupo limitado de elementos sensíveis ao contexto;

v) Para se determinar o conteúdo semântico de um proferimento de uma sentença é preciso seguir os seguintes passos: determinar 0 sentido dos componentes que não são sensíveis ao contexto, precisar as vaguidades, desambiguizar expressões ambíguas e fixar os conteúdos das expressões sensíveis ao contexto; o conteúdo 
semântico da sentença é obtido em função do conteúdo semântico de suas partes;

vi) O proferimento de uma sentença pode expressar outras proposições além da proposição que é o seu conteúdo semântico;

vii) Uma intuição sobre o conteúdo do ato de fala não é necessariamente uma intuição do conteúdo semântico de uma proposição.

Apesar de negar a influência do contexto no entendimento do significado da sentença, os minimalistas acreditam que existam termos que requerem 0 contexto para a compreensão; contudo, o uso do contexto é reivindicado pela combinação dos termos que compõem a sentença proferida. A esses termos, os minimalistas chamam de indexicais - também chamados de dêiticos - e eles podem ser desde pronomes, como advérbios e alguns verbos que indicam tempo (CAPPELEN; LEPORE, 2005). E essas expressões podem precisar de um contexto para que as condições de verdade de uma sentença sejam verificadas. Os minimalistas apresentam um número limitado de indexicais sensíveis ao contexto, e qualquer elemento fora desse conjunto não apresenta qualquer ameaça ao significado literal de uma proposição. Vejamos alguns exemplos de sentença com elementos que, segundo os minimalistas, necessitam de fatores contextuais:

b) Eu tenho 30 anos.

O pronome "eu" deixa uma lacuna aberta, ou seja, precisa do contexto para saber de qual pessoa estamos falando. Se, em um primeiro caso, é a pessoa Maria, logo é verdadeira, mas se fosse a mãe da Maria, seria falsa, pois a dona Nazaré tem 69 anos. Segundo Cappelen e Lepore (2005), o tempo verbal precisa ser específico, indicando quando e qual/quantas pessoas estão 
falando. No exemplo, o verbo conjugado "tenho" indica uma pessoa e no tempo presente, corroborando aquilo que os autores defendem que os elementos da sentença direcionam a ativação do contexto. Vejamos mais exemplos:

c) Hoje aconteceu uma rebelião em Manaus.

$\mathrm{Na}$ sentença acima, para que as condições de verdade sejam contempladas, é necessário o contexto para saber qual dia/data o hoje é referenciado. Neste caso, a sentença só será verdadeira se o "hoje" se referir ao dia 01 de janeiro de 2017 e a sentença tenha sido proferida na respectiva data. Qualquer interpretação diferente em relação ao advérbio "hoje" seriam inferências pragmáticas que nada influenciam na proposição.

Apesar de estabelecer "regras" e formas para a presença do contexto nas sentenças, o minimalismo não dá uma explicação clara e sistemática para alguns fenômenos da linguagem, tais como a metonímia, polissemia, ou mesmo para aquilo que está por "trás" do que foi literalmente dito. Há diversos fatores contextuais que, a depender do cenário e dos participantes da conversação, o sentido é compreendido de um modo diferente. Na próxima seção, vamos apresentar um pouco da teoria contextualista e apresentar alguns exemplos que permitem perceber a relevância do contexto em determinadas situações de fala.

\section{O contextualismo semântico}

O Contextualismo Semântico, cujos autores principais são Recanati (2010), Moravcsik (1998), Travis (2000) entre outros, que defendem uma tese contextualista mais moderada, e também Bezuidenhout (2002), mais radical, e também os mais tradicionais Austin (1975) e Searle (1969) representam uma corrente teórica contrária ao Minimalismo, ao menos em termos da oposição conteúdo semântico $x$ atos de fala. Como vimos, para o minimalista o conteúdo semântico é restrito às formas que compõem a sentença sem qualquer apelo a 
elementos contextuais, salve os indexicais e outros membros do conjunto básico. Os contextualistas, ao contrário, rompem com essa limitação, estabelecendo relação entre o conteúdo semântico de uma sentença e as inferências pragmáticas que fazemos a partir dele. Nessa relação, o contexto afeta ou modaliza a compreensão de uma determinada sentença, fazendo com que ela possa ter diferentes proposições, a depender da situação discursiva, estabelecendo diferentes condições de verdade.

Nesta seção, seguiremos a apresentação do contextualismo conforme defendido no livro Truth-Conditional Pragmatics de François Recanati (2010). Nele, o autor defende que o conteúdo semântico pode ser dependente do contexto para que as condições de verdade de uma sentença sejam contempladas, e a escolha de solicitar um contexto ou outro para a atribuição de verdade é opcional, ou seja, você pode depreender um significado x ou y, a depender da situação de conversação e dos fatores que estão envolvidos no ato de fala e até mesmo do conhecimento de mundo dos falantes.

Neste trabalho, não nos estenderemos a todos os conceitos explicados pelo autor, nossa proposta é extrair a ideia geral da teoria contextualista em sua forma moderada e apresentar o que ela traz de relevante em comparação ao minimalismo. Como mencionamos, há uma relação de dependência entre o conteúdo semântico de uma sentença e o contexto.

Uma sentença $x$ pode ter mais de uma condição de verdade, a depender do contexto em que se profere a sentença. Recanati (2010) acredita que não são apenas os indexicais que solicitam o contexto para preencher a lacuna do conteúdo semântico de uma sentença, há outros elementos que também requerem fatores externos para a compreensão do sentido e esses elementos podem estar ou não entre os constituintes de uma proposição. Por exemplo:

d) Pedro tem 5 filhos 
Se essa frase fosse analisada por um minimalista, a sentença deveria expressar um conteúdo semântico cuja condição de verdade seria o que está expresso literalmente na sentença; porém, na visão de um contextualista, segundo nossa análise, poderíamos depreender que Pedro: i) poderia ter mais filhos, mais que 5, neste caso, pelo menos 5 ele tem; ii) Pedro tem cinco filhos homens, se levar em consideração o gênero; iii) Pedro pode ter 3 filhas mulheres e 2 filhos homens (ou outras combinações na diferença de sexo dos filhos que resulte em cinco indivíduos, de modo que ainda permaneça o fato de que ele tem filhos e filhas).

Como pudemos analisar, outros significados são possíveis para uma única sentença em S. A depender do contexto, conforme elencamos acima, teríamos $S_{1}, S_{2}$ e $S_{3}$, e nos três contextos teríamos condições de verdade se: i) Pedro tem pelo menos 5 filhos; ii) Pedro tem 5 filhos homens, iii) Pedro tem filhos do sexo feminino e do sexo masculino, 5 no total. Com isso, a partir de uma única sentença, depreendemos três condições de verdade, cada uma correlacionada ao contexto específico acima. Essa interpretação vem daquilo que Recanati (2010) denomina de "Unarticulated Constituents", cujos elementos não estão presentes entre os constituintes de uma proposição, mas apenas em seu nível semântico. Para o contextualista, apesar de termos a possibilidade de obter essas interpretações, elas não são impostas, não são regras, ou seja, o indivíduo pode, intuitivamente, chegar a essas conclusões, diferentemente do minimalista que defende que cada asserção tem um único conteúdo semântico.

Há ainda outro modo de depreender diferentes significados de uma única asserção sem ter na sentença algum indexical. No exemplo anterior, as diferentes interpretações foram inferências ao conteúdo posto, e ambas poderiam apresentar conteúdo de verdade em cada ato específico e situação contextual. Contudo, não são apenas os indexicais ou os constituintes inarticulados que precisam do contexto para preencher o significado de uma sentença, há ainda elementos que por serem ambíguos necessitam de outros 
elementos externos para assegurar as condições de verdade de uma sentença, mesmo que os constituintes que a compõem não o requeiram. A esse processo Recanati (2010) chamou de "Modulação". Por exemplo:

e) There is a lion in the middle of the piazza (RECANATI, 2010, p. 5).

A palavra "leão" (tradução livre de 'lion') não é um indexical; todavia, na sentença ela se apresenta como tal, pois a proposição permite duas interpretações, abre lacunas para que as condições de verdade da sentença sejam contempladas. Logo, para uma sentença em $\mathrm{S}$ há duas possibilidades de intepretação, a depender do contexto do proferimento. Ela pode, por exemplo, significar que um leão, animal físico, esteja caminhando lentamente, procurando uma presa, na praça, ou mesmo um leão numa exposição circense. Outro significado possível é que há um leão, um objeto estátua, enfeitando a praça. Logo, para obter qual a condição de verdade da sentença, é necessária a presença do contexto, pois não podemos afirmar que a sentença tem sentido unívoco, principalmente se ela abre lacunas para dupla intepretação de sentido.

Outro exemplo, bastante comum para ilustrar a dependência do contexto na determinação do significado, consiste em se apelar para sentenças com quantificadores, como "todos", "algum", "nenhum". Dependendo do contexto, o significado de quantificadores como estes pode variar. Vejamos um exemplo:

f) Nenhum vereador ganha mais do que um professor.

Esta sentença pode ser entendida no contexto de uma Câmara de vereadores particular. Sendo entendida no contexto de um município específico, "nenhum" se aplica aos vereadores do município, e as condições de verdade da sentença indicam então que ela é verdadeira se nenhum vereador daquele local recebe um salário maior do que os professores do município. Todavia, podemos alterar o escopo do quantificador se supormos que a sentença foi proferida com 
o objetivo de falar de um pequeno grupo de vereadores de um município que fizeram um acordo para limitar seus salários, de modo a não ganhar mais do que os professores do município. Neste sentido, as condições de verdade da sentença indicariam que ela é verdadeira se nenhum vereador daquele grupo ganha mais do que um professor, mesmo que os vereadores da cidade, de modo geral, ganhem bem mais do que um professor. 


\section{O que está em jogo no debate?}

Como vimos, à primeira vista existem grandes diferenças entre as abordagens minimalista e contextualista. Elas são opostas de modo que não parece possível que uma delas seja verdadeira sem que isso implique que a outra seja falsa. Mas o que exatamente está em jogo no debate? O que podemos extrair de nossa discussão anterior que se possa dizer que seja o cerne da discussão? Nesta seção abordaremos este problema, baseados na compreensão da questão de Cappelen e Lepore $(2005,2006)$ e Recanati (2010). Como veremos, há muita concordância também, apesar da divergência nos termos empregados.

Segundo Recanati (2010, p. 2), a concepção contextualista surge para substituir uma concepção que ele chama de modular. 0 modo modular de encarar a relação entre semântica e pragmática separa ambas as esferas em módulos disjuntos. Primeiramente, segundo a abordagem modular, temos a capacidade ou competência semântica, que é a capacidade de compreendermos o significado de uma sentença. Nesta etapa da compreensão do significado de uma sentença, o contexto interfere minimamente, e sempre que esse for o caso, a necessidade de tal intervenção é indicada nas próprias expressões que requerem referência contextual para fixar seu sentido. Isso fica claro em sentenças como "eu sou brasileira", na qual a própria expressão "eu" requer que se utilize de recursos do contexto para fixar sua referência.

Em segundo lugar, na concepção modular vem a competência pragmática, nossa capacidade de compreender o que um falante afirma ao proferir um enunciado. Segundo a concepção modular, para se determinar o que o falante disse devemos trabalhar sobre o conteúdo semântico autônomo, de modo que a partir dele inferimos o que o falante disse. 0 conteúdo que é dito, em outras palavras, é pós-proposicional, ele depende da proposição expressa como conteúdo semântico para ser, de algum modo, inferido. Assim, a capacidade semântica tem precedência sobre a capacidade pragmática, com a 
segunda dependendo da primeira na abordagem modular (RECANATI, 2010, p. 16), sem que essa dependência possa ter sua direção alterada.

A concepção modular vem perdendo espaço, segundo Recanati, pois conforme vimos, os contextualistas fornecem evidências para o fato de que 0 conteúdo asserido depende não apenas dos sentidos das expressões componentes da sentença afirmada, mas também, de certo modo, do contexto de proferimento. Diferentemente do que propõe a abordagem modular, 0 conteúdo falado não é computado composicionalmente a partir de uma proposição mínima asserida pela sentença (RECANATI, 2010, p. 16). De fato, segundo Recanati (2010) há um crescente reconhecimento de que podem existir processos pragmáticos que interferem na composição do que é dito, mas que não são, de modo algum, iniciados ou disparados por componentes linguísticos da sentença. A associação da pragmática com a semântica é livre, e nesse sentido, a tese modular precisa ser deixada de lado, por não dar conta destes aspectos da comunicação. Vejamos a seguir um exemplo que indicaria essa interferência da pragmática na semântica e que não é dependente de nenhum tipo de necessidade de que as expressões sejam indicativas do significado. Considere a sentença abaixo:

g) A roupa de Joãozinho está limpa.

Suponha que ela foi proferida pelo professor de educação física de Joãzinho. No final de uma partida de futebol da escola, todos os estudantes que participaram do jogo estavam com as suas roupas totalmente encardidas, mas a de Joãzinho não. Apesar de sua roupa não ter acabado de sair de uma máquina de lavar roupa, e apesar de ele ter jogado a tarde inteira, a roupa de Joãozinho poderia ser considerada limpa quando comparada com a roupa de seus coleguinhas. Note que nossa interpretação não foi ativada por nenhum componente lexical da sentença " $\mathrm{g}$ ". Assim, o contexto parece interferir de modo livre na determinação do que foi dito. 
Todavia, apesar de permitir tamanha influência da pragmática na determinação do conteúdo de uma afirmação, a concepção de Recanati não é tão radical a ponto de negar qualquer conteúdo convencional básico aos componentes lexicais. Assim, por exemplo, não é caso que "limpa" somente possua significado em um contexto. De fato, a posição de Recanati aceita o que ele chama de Pressuposição Fregeana (RECANATI, 2010, p. 18):

- A maioria das expressões tem um sentido associado por convenção.

Ou seja, a maioria das expressões possui algum significado associado, independente do contexto (para ilustrar a origem fregeana do princípio, ver, por exemplo, a nota de rodapé $*$, em Frege (1960, p. 46), onde Frege afirma que, apesar dos diferentes modos de se apreender uma sentença ou termo, há um estoque comum de significados partilhados pela humanidade). Todavia, isso por si só não nos inclina a aceitar o que Recanati (2010, p. 18) chama de Hipótese de Frege:

- Uma expressão contribui para o sentido de um proferimento no qual é usada com o seu sentido associado por convenção.

Rejeitando a hipótese fregeana, cancelamos a tese de que a contribuição do sentido, associado por convenção a uma expressão, de certo modo fornece o sentido de todo o proferimento por alguma forma de composicionalidade ( 0 significado do todo sendo composto a partir dos significados atribuídos às partes). Note que não se trata aqui de recusar a composicionalidade, mas antes a afirmação de que as expressões possuem sentidos associados a elas de antemão, mesmo que apenas por convenção. Nesse sentido, fica aberto o espaço para que o sentido do proferimento seja determinado por fatores contextuais, compreendidos em sentido bastante amplo, inclusive por fatores não disparados pelas expressões compondo a sentença que foi proferida.

Acreditamos que os exemplos que vimos anteriormente ilustram bem esta teoria. Parece que um desafio significativo foi colocado para qualquer forma de minimalismo, afinal, na interpretação dos casos vistos acima o contexto parece interferir na determinação do significado de um proferimento. 
Todavia, parece que isso não é realmente difícil para determinadas formas de minimalismo semântico, em particular não para a versão defendida por Cappelen e Lepore. Note que na discussão acima, Recanati está focado em determinar o sentido de um proferimento, e em assegurar que este sentido não possa ser determinado exclusivamente pelo sentido associado com as expressões componentes da sentença proferida (negação da hipótese fregeana).

O problema todo parece ser que ao adotarmos a tese de que uma sentença expressa uma proposição mínima, o minimalista parece comprometido com a afirmação de que o conteúdo que é asserido ao se proferir esta sentença deve ou ser a própria proposição mínima ou, em alguns casos, ser inferido desta proposição. Isso elimina a possibilidade de influência pragmática livre, que é tão desejada pelos contextualistas como Recanati, pois para ele, algumas referências contextuais podem afetar o sentido das expressões e não somente o que está unilateralmente expresso em uma sentença. De fato, grande parte da tradição tem se mantido comprometida, pelo menos desde Frege, com a tese do Monismo dos Atos de Fala: um ato de fala expressa exatamente uma proposição (CAPPELEN; LEPORE, 2006, p. 427). Mas não é isso o que defendem Cappelen e Lepore. Esses autores minimalistas acreditam que o que se pode ser extraído do proferimento pode não ter nenhuma correlação com a proposição fixada.

De fato, Cappelen e Lepore (2005, p. 4-5) distinguem entre conteúdo semântico de uma sentença e conteúdo de um ato de fala. Já discutimos acima o conteúdo semântico de uma sentença, que é expresso por uma proposição mínima, a proposição comum a todos os atos de fala que enunciam a mesma sentença (CAPPELEN; LEPORE, 2005, p. 143). Segundo esta distinção traçada por Cappelen e Lepore, o conteúdo semântico não precisa estar vinculado ao conteúdo de proferimento. Assim, uma sentença pode ter determinado conteúdo semântico completamente determinado pelo sentido de seus componentes lexicais, sem que por isso o que é proferido seja dependente do 
contexto; o conteúdo de ato de fala pode, por seu turno, ser dependente do contexto de proferimento, sem que com isso o contexto influencie no conteúdo semântico (que, como vimos, depende apenas do conteúdo de seus componentes). Com essa separação entre conteúdo de atos de fala e conteúdo semântico é possível até mesmo que o conteúdo de um proferimento contrarie o conteúdo semântico de uma sentença. Um exemplo simples pode ilustrar isso. Considere a sentença:

h) $O$ presidente adora greves.

Uma vez que se tenha fixado a referência da expressão "o presidente" como sendo Michel Temer, podemos estabelecer facilmente condições de verdade para a sentença: "o presidente adora greves" se e somente se Michel Temer adora greves. Todavia, isso de modo algum esgota o que pode ser dito (afirmado, proferido) com uma sentença como esta. Alguém pode ser irônico ao pronunciá-la (como na sentença ' $a$ ', no início do texto), ao ser informado de que o presidente, por exemplo, deverá enfrentar uma greve, e neste contexto a sentença em questão, ao ser proferida, significa que o presidente, de fato, não gosta nem um pouco de greves. Certamente isso não poderia ser inferido do conteúdo semântico da sentença original apenas, dependendo do contexto para ser estabelecido (a sentença "A roupa de Joãozinho está limpa" pode ser analisada por um minimalista do mesmo modo, sem prejuízo para seu entendimento, pelo menos se levarmos em conta a distinção entre conteúdo semântico e conteúdo de atos de fala).

Esse exemplo e a distinção que fizemos acima ilustram o modo como o minimalista trata o problema levantado pelo contextualista: é possível manter algum tipo de independência entre semântica e pragmática, evitando a infiltração da pragmática na semântica. Para os teóricos minimalistas, a distinção entre conteúdo semântico e conteúdo dos atos de fala permite que a semântica se isole, de certo modo, da dependência do contexto presente na 
investigação daquilo que é comunicado em proferimentos particulares, e, ao ser conjugada com o pluralismo acerca dos atos de fala, fornece uma explicação de como o contexto é relevante na comunicação.

Com isso, o minimalista pode manter tanto a pressuposição de Frege quanto a Hipótese de Frege, desde que esta última diga respeito apenas ao conteúdo semântico. De fato, a composicionalidade é um componente básico do minimalismo semântico de Cappelen e Lepore (2005, p. 145). Não é demais enfatizar isso: ela fica restrita ao conteúdo semântico, e é apenas dele que o minimalismo semântico trata. Note que com isso Recanati parece poder abrir espaço para que haja uma proposição mínima expressa por uma sentença em função dos sentidos atribuídos aos componentes lexicais da sentença. $O$ que ele rejeita, aparentemente, é que o conteúdo proferido seja identificado com essa proposição mínima. Mas aqui já estamos tratando de outra coisa, segundo Cappelen e Lepore: do conteúdo de proferimento. De fato, a proposição mínima é uma das proposições proferidas por um proferimento, mas não necessita ser a única. Há uma mudança de conteúdo semântico para conteúdo de proferimento.

Esta distinção entre conteúdo semântico e conteúdo de proferimento é uma das chaves para se compreender $o$ debate entre minimalismo e contextualismo. Muitas coisas podem ser proferidas por um proferimento. 0 que o minimalista não admite, mas o contextualista defende, é que um proferimento, que por sua própria natureza depende do contexto, trate do conteúdo semântico de uma sentença. Identificar, de certo modo, o conteúdo de proferimento com o conteúdo semântico é o que Cappelen e Lepore (2005, p. 54) chamam de Hipótese equivocada (Misguided assumption), que adaptamos aqui:

- Se, ao tratarmos de um proferimento u de uma sentença $S$ em um contexto $C$, a intuição de que o conteúdo deste proferimento é a proposição $p$, então uma teoria semântica adequada deve atribuir $p$ como o conteúdo semântico deste proferimento. 
Esta hipótese, segundo os minimalistas, é o que está por trás do trabalho dos contextualistas. De acordo com os minimalistas, os contextualistas fazem uma análise do conteúdo de proferimentos, mas acabam identificando os mesmos como conteúdo semântico dos proferimentos. Isso faz com que a ideia de que o contexto tem relevância na semântica ganhe proeminência. Todavia, como vimos, o minimalista evita isso ao rejeitar essa hipótese.

Assim, a hipótese de Frege pode valer para o conteúdo semântico, mas não necessita valer para o conteúdo do ato de fala, no qual o contexto pode ter influência livre, opcional, como vimos. O ponto central é que Recanati trata do conteúdo dos atos de fala como parte da teoria semântica, enquanto que os minimalistas distinguem duas esferas de investigação.

Com isso estamos de volta ao tratamento modular, que Recanati repudia? Acreditamos que não. Segundo nosso entendimento, a concepção modular exigia que de algum modo o conteúdo semântico tivesse precedência sobre o conteúdo pragmático. Com o pluralismo dos atos de fala, que de fato concede aos contextualistas muito do que é dito sobre a influência do contexto, o que se tem é que o conteúdo semântico pode sim influenciar o conteúdo dos atos de fala em alguns casos, mas em outros casos, há uma necessidade de se apelar fortemente para o contexto para se determinar o que foi dito.

A disputa parece se focar em uma questão central: a distinção entre conteúdo asserido e conteúdo semântico. $O$ primeiro não precisa ser inferido do segundo, de acordo com o minimalismo. O contextualista nega isso, e coloca a tarefa da semântica como sendo determinar precisamente como podemos obter o conteúdo semântico a partir daquilo que é asserido em um contexto. Aparentemente, os a principal dificuldade no debate entre os oponentes nesta disputa versa não apenas acerca de como determinar o conteúdo semântico de uma sentença e de como devem ser entendidos os conteúdos dos proferimentos, mas antes, acerca de qual seria a definição precisa de semântica, de seu escopo e objetivos. 
Talvez podemos encontrar as raízes de ambas as abordagens aqui discutidas já em Frege (2009), um dos principais precursores da semântica formal, quando traça sua distinção entre sentido e referência de uma expressão. O sentido, como se sabe, é o "modo de se dar da referência" da expressão, a referência é apresentada através do sentido associado com a expressão. A referência é aquilo pelo que a expressão está por (um nome se refere a um objeto, por exemplo). Ao mesmo tempo que exige que o sentido seja objetivo, ou seja, que a humanidade partilhe um tesouro comum de sentidos das expressões (e essa seria uma condição para a própria possibilidade de se fazer ciência), Frege (2009) permite que diferentes falantes associem diferentes sentidos com a mesma expressão, dependendo do tipo de informação que possuem acerca da referência da expressão. Pessoas diferentes, um filósofo e alguém desinteressado da filosofia, por exemplo, associam diferentes sentidos com o nome "Aristóteles". Um deles pode ter conhecimento soficticado o bastante para associar com este nome o sentido "o autor dos Analíticos Posteriores", enquanto o outro poderia associar algo como "o discípulo mais famoso de Platão". Com isso, apesar de haver informação objetiva no sentido de um nome (o tesouro comum), que privilegia uma leitura minimalista, Frege também permite que elementos externos, contextuais interfiram para a determinação do sentido, e isso parece falar contra sua suposição de objetividade na determinação do sentido. Ou seja, existem elementos tanto do contextualismo quanto do minimalismo na discussão fregeana. Cada um deles privilegia um aspecto da distinção de Frege, e, ao mesmo tempo, recusa a importância do outro. É possível que isso indique tensões na própria obra pioneira de Frege, mas esse é um assunto que deixaremos para outra ocasião.

\section{Considerações Finais}


Depois de uma discussão complexa acerca do conteúdo semântico de uma sentença, o que podemos depreender é que o cerne da questão está na delimitação da fronteira do que é semântico e do que é pragmático. Por um lado, temos autores de uma perspectiva mais formalista, na qual o conteúdo semântico de uma sentença só pode ser influência pelo contexto através de um conjunto bem limitado de expressões (o basic set). Além desse basic set nenhum outro elemento, ou inferência feita a partir de uma proposição, pode ser assumido como influenciando na significação ou nas condições de verdade da sentença. Para o minimalista há somente um conteúdo semântico para cada expressão, o valor $\mathrm{x}$ é compreendido como valor $\mathrm{x}$ em qualquer contexto, não permitindo variação na compreensão.

Por outro lado, temos autores que dialogam com a perspectiva da linguagem proposta primariamente por Wittgenstein (1999) na qual defende a influência do contexto na condição de verdade de um conteúdo semântico. 0 que compreendemos da tese contextualista é que o contexto permite que um proferimento pode apresentar diferentes proposições, a depender do conhecimento de mundo da pessoa participante do discurso, das condições de produção da sentença e das condições de percepção da mesma. Aqui há uma interface entre o conteúdo semântico e os atos de fala, e essa relação é convencionada e selecionada, ou seja, a compreensão de um valor de verdade $x$ ou y e acionada pelo ouvinte parte da intuição despertada pelo contexto vigente ao ato de proferimento.

E um dos pontos de mais destaque e que nos fez depreender como cerne do debate foi a compreensão da própria tarefa da semântica. Ela deve tratar de sistematizar o estudo de alguma forma de conteúdo semântico comum a todos os atos de fala que proferem uma mesma sentença, ou deve buscar nas intuições disparadas por idiossincrasias do contexto de ato de proferimento o conteúdo de uma sentença? Aparentemente, a distinção entre 0 conteúdo de atos de fala e conteúdo semântico, se legítima. Além disso, nos ajudar a compreender o que está em jogo no que concerne a concepção de 
uma investigação de semântica. Uma vez que os termos do que está em disputa são mais claramente compreendidos, cabe aos debatedores entrarem em acordo acerca de como usarão estas palavras e contra qual concepção de semântica dirigirão seus esforços e argumentos. 


\section{Referências}

AUSTIN, John L.; URMSON, Jo O.; SBISÀ, Marina. How to do things with words. Cambridge: Harvard University Press, 1975.

BEZUIDENHOUT, Anne. Truth-conditional pragmatics. Philosophical Perspectives, Malden, MA, v. 16, p. 105-134, 2002.

CAPPELEN, H.; LEPORE, E. Insensitive Semantics - a defense of Semantic Minimalism and Speech Act Pluralism.

CAPPELEN, Herman; LEPORE, Ernest. Insensitive semantics. a defense of semantic minimalism and speech act pluralism. Hoboken, NJ: Blackwell Publishing, 2005.

CAPPELEN, Herman; LEPORE, Ernest. Précis of insensitive semantics. Philosophy and Phenomenological Research, Buffalo, NY, v. 73, n. 2, p. 425434, 2006.

FREGE, Gottlob Sobre o sentido e a referência. In: FREGE, Gottlob. Lógica e filosofia da linguagem. Tradução de Paulo Alcoforado. São Paulo: EdUSP, 2009. p. $129-158$.

FREGE, Gottlob. On concept and object. In: GEACH, Peter; BLACK, Max (ed.). Translations from the philosophical writings of Gottlob Frege. 2. ed. Oxford: Basil Blackwell, 1960. p. 42-55.

LEVINSON, Stephen C. Pragmática. São Paulo: Martins Fontes, 2007.

MORAVCSIK, Julius M. Meaning, creativity, and the partial inscrutability of the human mind. Stanford, CA: CSLI Publications, 1998.

RECANATI, François. Truth-conditional pragmatics. Oxford, NY: Clarendon Press, 2010.

SEARLE, John R. Speech acts. an essay in the philosophy of language. Cambridge, UK: Cambridge University Press, 1969.

TRAVIS, Charles. Unshadowed thought: representation in thought and language. Cambridge, MA: Harvard University Press, 2000.

WITTGENSTEIN, Ludwig. Investigações filosóficas. Tradução de José Carlos Bruni. São Paulo: Nova Cultural, 1999. 